\title{
Prevalence of tobacco use among women: a cross sectional survey from a squatter settlement of Karachi, Pakistan
}

\author{
Nousheen Iqbal ${ }^{1 *}$, Muhammad Irfan², Nida Ashraf ${ }^{3}$, Safia Awan ${ }^{4}$ and Javaid A. Khan²
}

\begin{abstract}
Background: While the prevalence of tobacco use has been slowly declining in the developed countries, rates have been steadily rising in the developing countries. This has led to a rapid rise in tobacco related lung diseases among women.

Objective: Determine the prevalence of tobacco use (both smoking and smokeless) among women in an urban squatter settlement (Orangi Town) in Karachi, Pakistan.

Methods: A cross-sectional survey was conducted on 19,325 females aged between 15 and 80 years in Orangi Town, an urban squatter settlement in Karachi, Pakistan. Modified questionnaire, developed by World Health Organization WHO and Global Adult Tobacco survey (GATS), was used in Urdu. A total of 16,987 women agreed to participate.

Results: The mean age was $37.3 \pm 9.8$ years amongst whom 15,255 (89.80\%) were married, 9143 (53.82 \%) admitted that at least one person uses tobacco in some form in their homes. The prevalence of smokeless tobacco was $42.25 \%$ (7178). The prevalence of smoking tobacco was low as compared to smokeless tobacco i.e. $18.0 \%$ (3058). Among smokers, $85.47 \%$ (1789) admitted that they had tried to quit smoking during last 12 months but failed.
\end{abstract}

Conclusion: Tobacco use among women in an urban squatter settlement is very high and alarming. Preventive and control measures against tobacco use are required in these communities.

Keywords: Tobacco, Women, Prevalence, Squatter settlement

\section{Background}

$\mathrm{T}$ Tobacco use is the leading cause of preventable mortality and morbidity worldwide [1, 2]. According to the WHO, tobacco use presently accounts for 6 million deaths each year [3]. Despite the increased awareness of hazardous effects of tobacco, it's use has risen amongst women. This has led to a dramatic surge in tobacco related lung diseases like lung cancer and chronic obstructive airway disease COPD amongst women. Tobacco can be used in different fashions, ranging from cigarette, pipe smoking and cigar to smokeless tobacco

\footnotetext{
*Correspondence: Naush_gr8smcian@hotmail.com

${ }^{1}$ Department of Pulmonary Medicine, Aga Khan University Hospital,

Stadium Road, Karachi, Pakistan

Full list of author information is available at the end of the article
}

products, available in various forms and mixtures like Pan/Betel quid, Naswar, Chalia/supari and Gutka.

According to Asian Agricultural Report 2014, Asia Pacific region is the fastest growing tobacco market in the world, with 4 out the 10 rapidly growing being: Malaysia, Indonesia, Pakistan \& Vietnam. According to the report of World Health Survey (2002-2003) carried out in Pakistan, the prevalence of any form of smoking tobacco amongst adults was $19.9 \%$ (33.5 \% for males and $6.2 \%$ for females) [4] and 1.8 and $4.6 \%$ for smoking and smokeless tobacco respectively amongst women in a nationwide survey conducted in 2012 [5]. In 2007, a study showed prevalence of smoking amongst Pakistani young adolescent female of $16.3 \%$ [6]. The mean age for trying to smoke cigarettes was 15 years.

There is a rapid increase in both use of smokeless tobacco as well as its inhaled forms [7]. Smokeless 
tobacco is the leading cause of cancers of the head and neck. In Pakistan and other Asian countries it's used in much more culturally acceptable forms like Hookah, Naswar, Betel Quid and Gutka. This is the reason why around $58 \%$ of these cancers worldwide occur in South and South East Asia alone [8,9] and they constitute a major burden in Pakistan. This necessitates that tobacco control strategies in Pakistan should be focused not only on cigarette smoking, but also on smokeless tobacco consumption. Level of education and poverty remain an important predictor of tobacco consumption among men and women [10]. Tobacco consumption is seen largely in low income poverty areas. There is a serious dearth of information regarding current prevalence of tobacco use in women especially amongst squatter settlements in Pakistan, where the prevalence is relatively higher than other parts of city due to low socio-economic status, So we planned to investigate the prevalence of tobacco use both smoking as well as smokeless form among adult women in an urban squatter settlement (Orangi Town) in Karachi, Pakistan in collaboration with The All Pakistan Women's Association (APWA) and the National Alliance for Tobacco Control (NATC).

\section{Methods}

A cross sectional survey was conducted during the period July 01, 2012 to December 31, 2012 in Orangi Town, which is an urban squatter settlement in Karachi, Pakistan. The approximate population is two million. A cross-sectional survey was carried out on nearly 19,325 females between the ages of $15-80$ years. There were total of 16,987 respondents. Face-to-face in-house interviews were conducted and a modified questionnaire developed by WHO and Global Adult Tobacco survey (GATS) [11], was used in Urdu. A brief training session was conducted and APWA female health workers were educated and fully trained to conduct this survey, a verbal consent was taken prior to the beginning of interview. All the surveyors gave standardized verbal explanations regarding this interview. Each interview took about $5 \mathrm{~min}$. The questionnaire included demographic characteristics, current smoking status, use of smokeless tobacco, awareness and usefulness of the warning sign on cigarette packs.

\section{Sampling strategy}

A cluster sampling technique was employed to draw the required sample. The Federal Bureau of Statistics (FBS) has divided the Orangi town into 13 union councils. The distance between the clusters ensured that the overall estimates are not influenced by factors peculiar to one geographic area. Trained community health workers explained the purpose and objectives of the study. Using software EPI Info and assuming $15 \%$ prevalence of smoking in the study population with $95 \%$ confidence level and a bound on error of $\pm 1 \%$ the estimated sample size was 4898 . For cluster sampling we need to incorporate the design effect. We calculated a design effect of 2.9. The sample size required after multiplying with design effect is: $n=4898 \times D=944 \times 2.9=14,204$. However, this sample size is inflated by $15 \%$, to account for nonresponders, making the final target sample size of 16,400 women.

The study was approved by Ethical review comity of NATC and ethical review board of APWA.

The analysis was carried out on SPSS v. 15. Frequencies were calculated for smokeless, smoked tobacco, nonsmokers, number of people using tobacco at home and passive smoking. Mean and standard deviation was calculated for age.

\section{Results}

From July 01, 2012 to December 31, 2012, a total of 19,325 inhabitants were approached and 16,987 agreed to participate. The mean age was $37.3 \pm 9.8$ (range 15-80) and $15,255(89.80 \%)$ of the respondents were married (Table 1).

It was discovered that about $53.82 \%$ (9143) of the households had at least one or more member in their family using tobacco in one form or another. Primarily, the most common form of tobacco use amongst women was smokeless $42.25 \%$ (7178), $18 \%$ (3079) were using smokeless tobacco while $5 \%$ (849) of women were using both. Out of $18 \%$ (3079) women who smoked tobacco, $67.95 \%$ (2093) smoked cigarettes, $26.43 \%$ (814) smoked Sheesha and $5.62 \%$ (173) smoked Huqqa (Table 2).

The prevalence of passive smoking was $12.1 \%$. A total of 2093 people who smoked cigarette, were asked the question whether they had tried to quit smoking over the last 12 months, $85.47 \%$ (1789) admitted that they

\section{Table 1 Demographics of the study population}

\begin{tabular}{lcc}
\hline Variables & Total number $(\mathbf{n}) \mathbf{1 6 , 9 8 7}$ & Percentages \\
\hline Age & & \\
$<30$ & 4570 & 26.9 \\
$30-45$ & 7304 & 43.0 \\
$>45$ & 5113 & 30.1 \\
Marital status & & \\
$\quad$ Married & 15,255 & 89.80 \\
Single & 1189 & 6.99 \\
Divorced & 510 & 3.01 \\
Widowed & 33 & 0.20 \\
Profession & & \\
Working women & 5662 & 33.33 \\
House wife & 11,325 & 66.67 \\
\hline
\end{tabular}


Table 2 Prevalence of tobacco use

\begin{tabular}{lll}
\hline Variables & Total number (n) 16,987 & Percentages \\
\hline Smokeless & 7178 & 42.25 \\
Smoking & 3079 & 18 \\
Mixed & 849 & 5 \\
No. of family members using tobacco at home & \\
0 & 6732 & 39.63 \\
1 & 9142 & 53.82 \\
2 & 99 & 0.58 \\
$>3$ & 1014 & 5.97 \\
Passive smoking & 2054 & 12.1 \\
Form of smoking tobacco & $\mathrm{n}=3079$ & 67.95 \\
Cigarette & 2093 & 26.43 \\
Sheesha & 814 & 5.62 \\
Huqqa & 173 & \\
Smoking status & & 98 \\
Daily & 2052 & 1.95 \\
Sometimes & 41 & \\
\hline
\end{tabular}

had tried to quit smoking but failed while $79.21 \%$ (1658) revealed that they had received medical advice to quit smoking. It was seen that majority of women $74.55 \%$ $(12,664)$ had not read any information in the newspapers regarding the harmful effects of smoking. However, there was a unanimous agreement that the picture on the cigarette pack showing hazards of tobacco use does deter them from smoking. At the end of this interview education on the hazardous effect of tobacco both smoking and smokeless was also provided by community health worker and $99.9 \%$ promised to quit this habit.

\section{Discussion}

Our study is the largest study that has been done amongst women in squatter settlement (Orangi town) Karachi, Pakistan to determine the prevalence of tobacco use both smoking and smokeless. Although surveys have been conducted in past to determine the prevalence of smoking tobacco, no such studies have yet been conducted in Pakistan for smokeless tobacco. The study has revealed that smokeless tobacco use is growing and its prevalence has increased to $42.25 \%$. Smoking tobacco use has mounted up to $18 \%$ as compared to the national household survey done in Pakistan 2012 where tobacco use among female was negligible [5]. A cross-sectional survey conducted in Madaripur, Bangladesh showed the prevalence of smokeless tobacco amongst women to be $25 \%$ [12]. The use of other forms of tobacco amongst females prevailed more than cigarettes in the present study. This may be because of greater cultural acceptability of these tobacco products over cigarettes among females in this region [9]. Betel Quid is served to guests in social gatherings and wedding ceremonies. Women are gifted Pandaan as a part of their trousseau/dowry. According to the 2011 WHO Report on the Global Tobacco Epidemic, Pakistan scores very poorly in terms of compliance with smoke-free legislation for public places. Considering the prevalence of culturally acceptable forms of tobacco among females, it is a cause for concern that there is no regular monitoring of smokeless tobacco in the country, nor are there any health warnings on smokeless tobacco products [13]. Women and youth in the developing world have been the target for most of these tobacco advertising tactics and there is an increase in smoking prevalence amongst women in these countries [14]. In our study the prevalence of smoking tobacco is $18.11 \%$ and passive smoking incidence $12.1 \%$ which is also high compare to last surveys done $[4,5]$. It has been shown that smoking restrictions at home not only reduce the overall exposure of tobacco, but it can also reduce the smoking practice in youth [15]. A study done in Liaquat University Hospital, Hyderabad in pregnant women showed peer pressure and depression to be the two major reasons for commencement of tobacco, especially smoking use, among women [16]. These figures reflect the dire need to strengthen public health efforts that curtail all forms of tobacco advertisement, sponsorship and marketing strategies as well as to enforce strict laws to ban the use of not only cigarette but also smokeless tobacco.

Our analysis revealed that $79.21 \%$ had been advised by their doctor to quit smoking and $85.47 \%$ of the subjects had attempted to quit smoking during the past 12 months but failed. Quitting smoking is not easy and services for helping smokers to quit smoking are also limited in Pakistan [13]. Among current smokers in the United States, $68.8 \%$ report that they want to stop smoking altogether and the number of former smokers has increased compared to the current smokers in the past 12 years [17]. This highlights the importance of these services in Pakistan to help those individuals who really wants to quit as majority are willing and failed due to ineffective cessation programs.

All respondents showed very limited knowledge about hazards of smoking $74.55 \%$ had not read any information in the newspaper regarding the harmful effects of smoking however there was also a unanimous agreement amongst the smokers that the pictorial warning on the cigarette pack discourage them from smoking. This is consistent with International Tobacco Control surveys which also revealed the greater potential of pictorial warnings over text-only warnings [18]. Though cigarette packs in Pakistan contain pictorial health warnings, smokeless tobacco products do not. A study done in Canada revealed that pictorial health warnings on smokeless tobacco products were more effective in reducing its 
appeal [19]. These effects would also be more profound in countries like Pakistan. Currently Pakistan is facing double burden with communicable as well as non-communicable diseases (NCD) causing morbidity and mortality. According to estimation, nearly $54.9 \%$ of the deaths in the country are caused by NCDs [20] and tobacco use is one of the biggest preventable risk factor.

\section{Limitations}

Our study is largest study but there are certain limitations, first our survey mainly done at home during day time so majority were married, second we are failed to address the different form of smokeless tobacco as there were so many products available with different names, third ethnicity was not asked in this survey. As it was a questionnaire-based study, also introduces an element of recall bias. Finally, the data are based on self-reporting and their responses pertaining to smoking and smokeless tobacco were not biologically validated.

\section{Conclusion}

So in conclusion tobacco use amongst women in an urban squatter settlement is alarmingly high. But good thing is majority of women are willing to quit this habits. Given the high morbidity and mortality associated with tobacco consumption, regulatory authorities need to enforce firm laws that ban the advertisement and promotion of all forms of tobacco. Current law in Pakistan only covers smoking tobacco, there is no law on smokeless tobacco and there is a need of law and legislation on smokeless tobacco too. They should also focus on having pictorial health warnings on smokeless tobacco products, the prevalence of which is higher amongst women with lower literacy rate. Meanwhile, there should also be a nationwide campaign in educating the masses against the dangers of not only smoking but also against smokeless tobacco, doctors and the media should play their roles in creating awareness and spreading information regarding its ill effects. Effective cessation programs are also necessary as majority is willing to quit. In last we recommend periodical survey and interventional studies in this high risk population to stop this tobacco epidemic.

\begin{abstract}
Authors' contributions
$\mathrm{NI}$ has made contributions to conception and design, interpretation of data, drafting the manuscript and revising it critically for important intellectual content. MI has made contributions to conception and design, interpretation of data, drafting the manuscript and revising it critically for important intellectual content. NA has made contributions to interpretation of data, drafting the manuscript. SA has made contributions to acquisition and interpretation of data; and in drafting the manuscript. JAK has made contributions in planning of survey acquisition and interpretation of data; and in drafting the manuscript. All authors read and approved the final manuscript.
\end{abstract}

\footnotetext{
Author details

${ }^{1}$ Department of Pulmonary Medicine, Aga Khan University Hospital, Stadium Road, Karachi, Pakistan. ${ }^{2}$ Department of Medicine, Aga Khan University,
}

Stadium Road, Karachi, Pakistan. ${ }^{3}$ Aga Khan University Hospital, Stadium Road, Karachi, Pakistan. ${ }^{4}$ Department of Medicine, Aga Khan University Hospital, Stadium Road, Karachi, Pakistan.

\section{Acknowledgements}

We are grateful to the contribution of the research team of the All Pakistan Women's Association who worked very hard to gather quality data within the required time frame. We also acknowledge the study participants for their valuable time And National Alliance of Tobacco Control (NATC). This study was funded by National Alliance of Tobacco Control (NATC) and All Pakistan Women's Association (APWA)

\section{Compliance with ethical guidelines}

\section{Competing interests}

The authors declare that they have no competing interests.

Received: 6 September 2015 Accepted: 16 September 2015

Published online: 24 September 2015

\section{References}

1. Murray CJ, Lopez AD. Mortality by cause for eight regions of the world: Global Burden of Disease Study. Lancet. 1997;349(9061):1269-76.

2. Mokdad AH, Marks JS, Stroup DF, Gerberding JL. Actual causes of death in the United States, 2000. JAMA. 2004;291(10):1238-45.

3. World Health Organization. WHO Report on the Global Tobacco Epidemic. 2013.

4. World Health Survey, Pakistan; 2002-03. (http://www.who.int/healthinfo/ survey/whspak-pakistan.pdf).

5. Gilani SI, Leon DA. Prevalence and sociodemographic determinants of tobacco use among adults in Pakistan: findings of a nationwide survey conducted in 2012. Popul Health Metr. 2013;11: 16. Published online 2013 September 3. doi: 10.1186/1478-7954-11-16.

6. Ganatra HA, Kalia S, Haque AS, Khan JA. Cigarette smoking among adolescent females in Pakistan. Int J Tuberc Lung Dis. 2007;11(12):1366-71.

7. Abernathy TJ, Bertrand LD. The prevalence of smokeless tobacco and cigarette use among sixth, seventh and eighth grade students: a longitudinal investigation. Can J Public Health. 1992;83(1):158.

8. Mazahir S, Malik R, Maqsood M, Merchant KA, Malik F, Majeed A, et al. Socio-demographic correlates of betel, areca and smokeless tobacco use as a high risk behavior for head and neck cancers in a squatter settlement of Karachi, Pakistan. Subst Abuse Treat Prev Policy. 2006;1:10.

9. Gupta PC, Ray CS. Smokeless tobacco and health in India and South Asia. Respirology. 2003;8(4):419-31.

10. Rani M, Bonu S, Jha P, Nguyen SN, Jamjoum L. Tobacco use in India: prevalence and predictors of smoking and chewing in a national cross sectional household survey. Tob Control. 2003;12(4):e4.

11. Global Adult Tobacco Survey Collaboration Group. Tobacco questions for surveys: a subset of key questions from the Global Adult Tobacco survey(GATS). 2nd ed. Atlanta: Centers for Disease Control and Prevention (CDC); 2011.

12. Hossain MS, Kypri K, Rahman B, Arslan I, Akter S, Milton AH. Prevalence and correlates of smokeless tobacco consumption among married women in rural Bangladesh. PLoS One. 2014;9(1):e84470. doi:10.1371/ journal.pone.0084470.eCollection.

13. World Health Organization. WHO report on the global tobacco epidemic: warning about the dangers of tobacco. Country profile: Pakistan. http:// www.who.int/tobacco/surveillance/policy/country_profile/pak.pdf.

14. Richmond RL. How women and youth are targeted by the tobacco industry. Monaldi Arch Chest Dis. 1997;52(4):384-9.

15. Wakefield MA, Chaloupka FJ, Kaufman NJ, Orleans CT, Barker DC, Ruel EE. Effect of restrictions on smoking at home, at school, and in public places on teenage smoking: cross sectional study. BMJ. 2000;321(7257):333-7.

16. Das CM, et al. Frequency, knowledge and practice of tobacco smoking in pregnant women at out patient department of a Tertiary Care Hospital. JLUMHS. 2012;11(03):176.

17. Centers for Disease Control and Prevention (CDC). Quitting smoking among adults: United States, 2001-2010. MMWR Morb Mortal Wkly Rep. 2011;60(44):1513-9. 
18. Fong GT, Hammond D, Hitchman SC. The impact of pictures on the effectiveness of tobacco warnings. Bull World Health Organ. 2009;87(8):640-3.

19. Callery WE, Hammond D, O'Connor RJ, Fong GT. The appeal of smokeless tobacco products among young Canadian smokers: the impact of pictorial health warnings and relative risk messages. Nicotine Tob Res. 2011;13(5):373-83. doi:10.1093/ntr/ntr013 Epub 2011 Feb 28.
20. Nishtar S, Boerma T, Amjad S, Alam AY, Khalid F, UlHaq I, et al. Pakistan's health system: performance and prospects after the 18th Constitutional Amendment. Lancet. 2013;381(9884):2193-206. doi: 10.1016/S01406736(13)60019-7. Epub 2013 May 17.

Submit your next manuscript to BioMed Central and take full advantage of:

- Convenient online submission

- Thorough peer review

- No space constraints or color figure charges

- Immediate publication on acceptance

- Inclusion in PubMed, CAS, Scopus and Google Scholar

- Research which is freely available for redistribution

Submit your manuscript at

www.biomedcentral.com/submit

(O) Biomed Central 